\title{
Mortality, morbidity, and psychosocial outcomes of persons spinal cord injured more than 20 years ago
}

\author{
G G Whiteneck PhD, ${ }^{1} \mathrm{~S}$ W Charlifue MA ${ }^{1}{ }^{\mathrm{H}} \mathrm{L}$ Frankel MB FRCP ${ }^{2} \mathrm{M}$ H Fraser BM \\ FRCS,${ }^{3} \mathrm{~B}$ P Gardner MA MRCP FRCS, ${ }^{2} \mathrm{~K}$ A Gerhart MS, ${ }^{1} \mathrm{~K}$ R Krishnan MD \\ FRCS,${ }^{3}$ R R Menter MD,${ }^{1}$ I Nuseibeh FRCS, ${ }^{2}$ D J Short MRCP,${ }^{2} \mathrm{~J}$ R Silver MB BS \\ $\mathrm{FRCP}^{2}$ \\ ${ }^{1}$ Rocky Mountain Regional Spinal Injury System, Craig Hospital, Englewood, Colorado, \\ USA; ${ }^{2}$ National Spinal Injuries Centre, Stoke Mandeville Hospital, Aylesbury, England; \\ ${ }^{3}$ The Regional Spinal Injuries Centre, Southport, England.
}

\begin{abstract}
Mortality, morbidity, health, functional, and psychosocial outcomes were examined in 834 individuals with long term spinal cord injuries. All were treated at one of two British spinal injury centres: the National Spinal Injuries Centre at Stoke Mandeville Hospital or the Regional Spinal Injuries Centre in Southport; all were 20 or more years post injury. Using life table techniques, median survival time was determined for the overall sample (32 years), and for various subgroups based on level and completeness of injury and age at injury. With the number of renal deaths decreasing over time, the cause of death patterns in the study group as it aged began to approximate those of the general population. Morbidity patterns were found to be associated with age, years post injury, or a combination of these factors, depending upon the particular medical complication examined. A current medical examination of 282 of the survivors revealed significant declines in functional abilities associated with the aging process. Declines with age also were found in measures of handicap and life satisfaction, but three quarters of those interviewed reported generally good health and rated their current quality of life as either good or excellent.
\end{abstract}

Key words: spinal cord injuries; long term survival; quality of life; morbidity; mortality.

\section{Introduction}

Prior to World War II, survival following spinal cord injury was relatively rare. However, medical advances made over the past decades have greatly enhanced both the immediate and the long term survival of individuals with spinal cord injuries. Foremost has been the development of spinal injury treatment centers with early patient transfer and specialized team-oriented rehabilitation. Additionally, the development of sulfa drugs in the 1940s, antibiotics in the 1950s and 1960s, and improved emergency medical services in the 1960s and 1970s, have contributed to survival. ${ }^{1}$

When this improved survival is coupled with the fact that spinal cord injuries typically occur in early adulthood, ${ }^{2-4}$ it becomes clear that those currently sustaining such injuries are likely to face several decades of living with the consequences of severe disability. Unfortunately, the information and experiences these aging survivors and their care givers have to draw upon are limited.

First, although increasing steadily, the number of individuals who have already survived two or more decades with spinal cord injuries is relatively small. Second, although researchers have paid significant attention to initial rehabilitation, to short term medical, functional, and psychological outcomes $^{3.4}$ and even to predicting the long term costs of spinal cord injury, ${ }^{5-7}$ they have devoted considerably less attention to long term health, medical, and psychosocial outcomes and issues associated with aging. The works of Creek et al, ${ }^{8}$ Hoad et al, ${ }^{9}$ and Zarb et $a l^{10}$ have recently addressed community integration, quality of life, perceptions of changes in health and functional status, and 
other psychosocial issues among populations of long term spinal cord injury survivors; however, systematic research efforts of similar breadth or which simultaneously examine morbidity and mortality, are few in number. In large part, it has been widely recounted anecdotal reports, particularly by individuals such as Corbet, ${ }^{1}$ Hohmann, ${ }^{12}$ and Trieschmann, ${ }^{13}$ which have stimulated much of the present interest in and concern with aging and spinal cord injury.

To address the outcomes of long term spinal cord injury more comprehensively, the present investigation was undertaken. The purpose of this study was to evaluate the lifetime health and functional status of persons spinal cord injured more than 20 years ago. Outcomes which were assessed included mortality, morbidity, current health status, current functional limitations, social reintegration, psychological adjustment, quality of life, and perceptions of change in health and functional status over the decades.

\section{Methodology}

Two facilities were identified which have treated and maintained complete initial hospitalization and follow up medical records for individuals who sustained spinal cord injuries from as long ago as 1943: The National Spinal Injuries Centre at Stoke Mandeville Hospital in Aylesbury, England, and the Regional Spinal Injuries Centre in Southport, England. Preliminary selection criteria included persons who sustained traumatic spinal cord injuries prior to December 31, 1970 and were 15 to 55 years old at the time of injury. This ensured that all participants were at least 20 years post injury at the time the study was conducted, and eliminated both childhood injuries and injuries in older adults who already were likely to have experienced considerable aging prior to the onset of their disabilities.

Study eligibility was further limited to those individuals whose residence at the time of injury was in a 13-county catchment area surrounding the two centres. This geographic restriction ensured not only that the sample was population based, but also that subjects were more likely to have utilized the two centres for ongoing follow up care.

The only other study criteria required that subjects had been admitted to one of the two centres within one year of initial injury and that they had survived the first year of injury. The former ensured early intervention by specialized centres and eliminated individuals who had generated substantial medical record information at other facilities which would be unavailable to the investigators; the latter ensured that, as an investigation of aging, the focus was on long term outcomes rather than acute deaths.

Eight hundred and thirty-four individuals met all of the study criteria. Demographically, $87 \%$ were males and $13 \%$ were females. Age distribution at the time of injury is shown on Table $I$, as is the distribution by years post injury at the time the study was conducted. Etiologies of the initial injuries and distribution of injuries by level and severity also are shown on Table I.

To perform mortality, morbidity, and outcome analyses, study subjects were separated into groups based on survival status. This was determined using a several step process. First, thorough review of the 834 subjects' in- and outpatient records at the two participating centres was conducted. Second. Office of Population Censuses and Surveys (OPCS) records were searched for the 834 study subjects. For those known to have died, death certificates were obtained. For others, appropriate local health authorities were contacted to further confirm survival status and obtain current addresses. Third, those identified as survivors were contacted and recruited to participate in a one day comprehensive medical reevaluation and health status interview at the participating centres.

These procedures confirmed that:

1362 individuals ( $43 \%$ of the study group) had expired.

$2412(49 \%)$ were surviving. Of these, 282 $(68 \%)$ were contacted and ultimately completed the comprehensive reevaluation and interview; $111(27 \%)$ were contacted, but declined to participate in 
Table I Study group characteristics

Percent of total

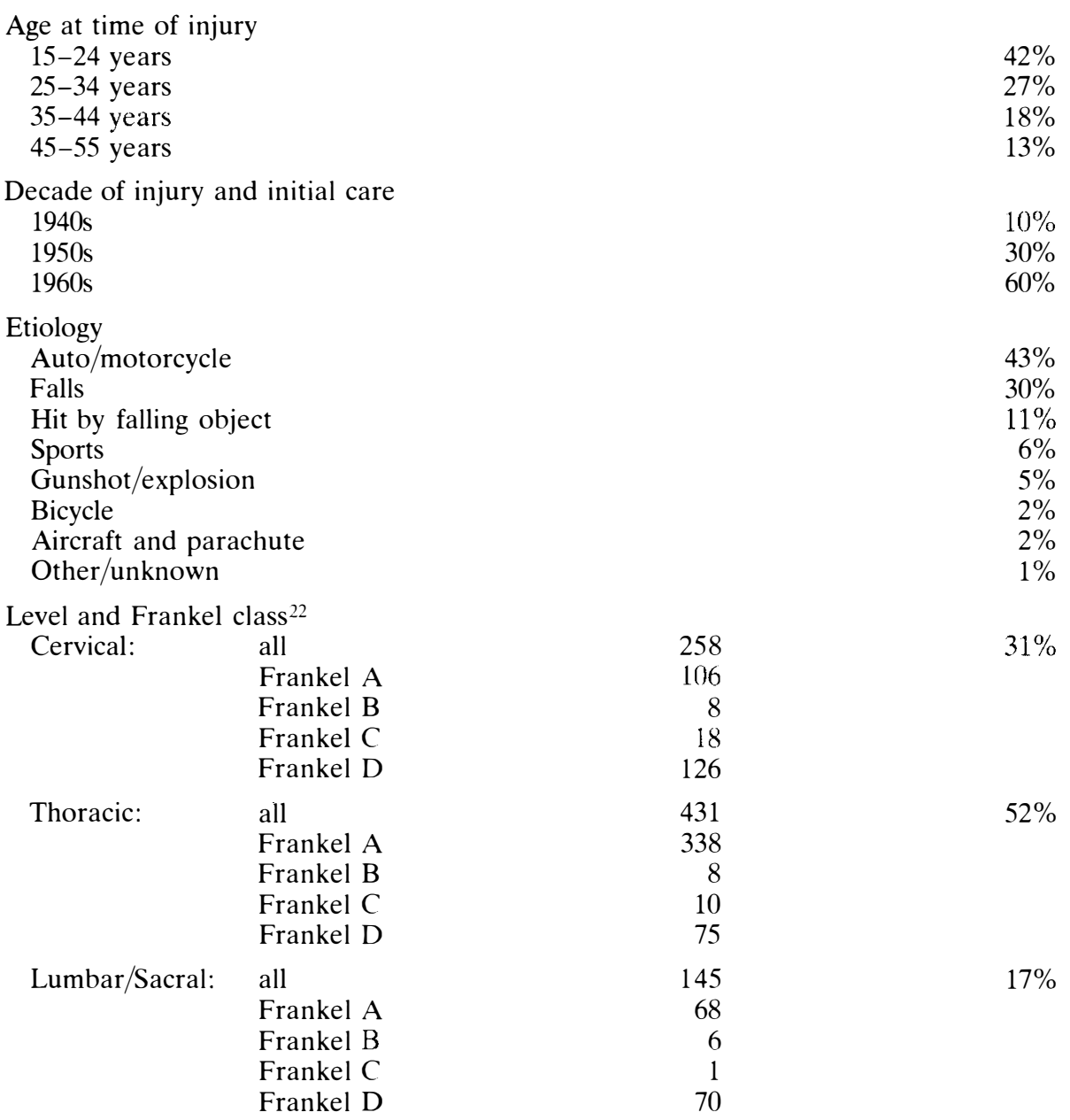

the reevaluation; and $19(5 \%)$ could not be contacted.

360 individuals $(7 \%)$ were lost to both the SCI centres and the OPCS. Their survival status could not be determined. Therefore, they were withdrawn alive at the point of their last documented contact at one of the centres.

Standard life table techniques were utilized to analyze survival rates, ${ }^{14}$ and mortality odds ratios were computed separately for level of injury, completeness of injury, age at injury, gender, and the era of care, while statistically controlling for the other factors using Cox Proportional Hazards Regression. ${ }^{15}$ Gender-weighting techniques were used to account for varied mortality patterns by sex in the general population. Since the ratio of males to females in the study sample was $7: 1$, the same ratio was used to gender-weight the age specific mortality data for the general population. This provided comparable statistical comparison between the SCI sample and their expected mortality if not disabled.

Morbidity and other health, medical, and psychosocial outcome analyses were then performed. ICD-9-CM diagnosis and procedure $\operatorname{codes}^{16}$ were identified using data 
abstracted from all subjects' available initial and follow up in- and outpatient medical records, from the death certificates of those who had died, from available autopsy reports, and from the comprehensive reevaluation history and physical reports of the 282 participating survivors. From the entire study group, 27,755 ICD-9 codes representing individual procedures and individual episodes of a diagnosis were collected. Seventy percent of these represented complications and problems which occurred after the initial hospitalization, during the follow up years.

Compilation of these codes permitted identification, ranking, and analysis of causes of mortality for the 362 who had died, and hospitalizations and illnesses (morbidity) for the entire sample of 834 . Finally, separate examination and analysis of the results of the 282 physical examinations were done. For the latter group, results of laboratory tests done during that physical examination were compared with data from a British age related non disabled population. ${ }^{17}$

The health status interview of the 282 participants who completed the physical examination not only provided information regarding self perceptions of changes in health over time and psychosocial concerns, but utilized several instruments to assess social functioning, perceived wellbeing, life satisfaction and quality of life.

Societal functioning was measured with the Craig Handicap Assessment and Reporting Technique (CHART). ${ }^{18}$ This instrument measures the degree to which individuals with disabilities are reintegrated back into the community; in other words, the extent to which they are 'handicapped'. Five specific dimensions or domains of handicap make up the CHART instrument: physical independence, mobility, occupation, social integration, and economic self sufficiency. Scores for each of these dimensions, as well as the total CHART score, are based on normative expectations for non disabled members of society.

Perceived wellbeing and life satisfaction were also assessed. In addition to self ratings of quality of life over time, the 282 Health Status Interview participants com- pleted the Index of Psychological Wellbeing, ${ }^{19}$ which asks individuals to indicate whether they never, sometimes, or often feel one of 8 ways, such as 'very lonely or remote from other people', or 'on top of the world'. Participants also completed the Life Satisfaction Index $^{20}$ in which they were asked to agree or disagree with statements such as 'these are the best years of my life', and The Quality of Life and Individual Needs Questionnaire ${ }^{21}$ in which they responded to 15 quality of life categories by indicating how important each factor was to them, and how well their needs and wants were being met in that category.

The results of the administration of these instruments were analyzed by age, neurological level, and years post injury. Together, these tools assessed the subjective component of quality of life and perceived wellbeing, while the more objective component of quality of life-social role fulfillment - was measured by CHART.

\section{Results}

\section{Survival}

Using standard life table techniques, the median survival time for all cases was determined to be 32 years. Eighty-five percent of the group was surviving at 10 years, $71 \%$ at 20 years, $53 \%$ at 30 years, and $35 \%$ at 40 years. In terms of the era in which the injury was incurred and initial care was received, the median survival for those injured during the 1940s was 26 years, while the median survival for those injured in the 1960 s is estimated at 33 years. In addition, median survival times were slightly longer for those with incomplete injuries (Frankel $\mathrm{B}, \mathrm{C}, \mathrm{D}$, or $\mathrm{E}^{22}$ ), as well as those persons with thoracic or lumbar injuries. Survival status by level and severity of injury and age at injury are illustrated in Table II.

Mortality odds ratios were computed separately to control for such factors as level of injury, completeness of injury, age at injury, gender, and the era of care, while statistically controlling for the other factors. ${ }^{15}$ All factors were statistically significant except gender.

The mortality odds ratio for quadriplegia compared to paraplegia was 1.4 , indicating 
Table II Survivala

\begin{tabular}{|c|c|c|c|c|c|c|}
\hline \multirow{2}{*}{$\begin{array}{l}\text { Age and } \\
\text { Group }\end{array}$} & \multirow[b]{2}{*}{ Number } & \multicolumn{4}{|c|}{ Percent survivingb } & \multirow{2}{*}{$\begin{array}{c}\text { Median } \\
\text { years }\end{array}$} \\
\hline & & 10 years & 20 years & 30 years & 40 years & \\
\hline \multicolumn{7}{|l|}{$<30$ at injury } \\
\hline Complete quad & 66 & $86 \%$ & $77 \%$ & $64 \%$ & $\mathrm{NA}^{\mathrm{c}}$ & \\
\hline Incomplete quad & 87 & $96 \%$ & $85 \%$ & $67 \%$ & $31 \%$ & 36 yrs \\
\hline Complete para & 233 & $91 \%$ & $79 \%$ & $63 \%$ & $47 \%$ & 36 yrs \\
\hline Incomplete para & 96 & $96 \%$ & $89 \%$ & $76 \%$ & $65 \%$ & $44 \mathrm{yrs}^{\mathrm{d}}$ \\
\hline \multicolumn{7}{|l|}{ 30-49 at injury } \\
\hline Complete quad & 33 & $71 \%$ & $42 \%$ & $34 \%$ & $\mathrm{NA}^{\mathrm{c}}$ & $17 \mathrm{yrs}$ \\
\hline Incomplete quad & 50 & $70 \%$ & $63 \%$ & $33 \%$ & $0 \%$ & $26 \mathrm{yrs}$ \\
\hline Complete para & 159 & $81 \%$ & $60 \%$ & $36 \%$ & $12 \%$ & 23 yrs \\
\hline Incomplete para & 64 & $84 \%$ & $69 \%$ & $47 \%$ & $16 \%$ & $29 \mathrm{yrs}$ \\
\hline \multicolumn{7}{|l|}{$50+$ at injury } \\
\hline Complete quad & 7 & $53 \%$ & $0 \%$ & $0 \%$ & $0 \%$ & $10 \mathrm{yrs}$ \\
\hline Incomplete quad & 15 & $56 \%$ & $24 \%$ & $0 \%$ & $0 \%$ & $11 \mathrm{yrs}$ \\
\hline Complete para & 14 & $50 \%$ & $17 \%$ & $0 \%$ & $0 \%$ & $12 \mathrm{yrs}$ \\
\hline Incomplete para & 10 & $67 \%$ & $44 \%$ & $\mathrm{NA}^{\mathrm{c}}$ & $\mathrm{NA}^{\mathrm{c}}$ & 14 yrs \\
\hline
\end{tabular}

aFirst year deaths excluded from the study

bUsing Standared Life Tables

cNo study cases in this group have been injured for 40 years

${ }^{\mathrm{d}}$ Estimated median survival

that after controlling for the other factors, the mortality rate was 1.4 times higher for persons with quadriplegia than paraplegia. Similarly, the mortality odds ratio was 1.5 for persons with complete injuries compared to those with incomplete injuries. It was 9.7 times higher for persons injured over age 50 compared to those injured under age 30 , and it was 2.7 times higher for ages 30 to 49 . Finally, for era of care, the mortality rate was 1.7 times higher for persons injured in the 1940 s compared to the $1960 \mathrm{~s}$; it was 1.3 times higher for those who were injured in the $1950 \mathrm{~s}$.

In comparing data with those of the general population, mortality rates increase dramatically with age in both those with spinal cord injuries and the general population. Comparisons between the mortality rates of the two groups, therefore, must be made among similar age and gender groups. Figure I graphically presents the mortality rates of persons with spinal cord injury and the general population (gender weighted) between the ages of 20 and 70 .

Not only do both mortality curves increase exponentially with age, but the extra mortality due to spinal cord injury also increases with age. In the 20 to 30 age range, the extra spinal cord injury mortality is approximately 7 deaths per 1000 higher than the general population while in the 60 to 70 age range, the extra spinal cord injury mortality is about 25 deaths per 1000 higher.

On the other hand, the mortality ratio of persons with spinal cord injury compared to the general population decreases with age. At age 20, persons with spinal cord injury have a mortality rate 8 times higher than the general population ( 7.2 per 1000 compared to 0.9 per 1000 ). However, by age 70 , survivors of spinal cord injury have a mortality rate only 1.5 times higher than the general population (75.1 per 1000 compared to 50.2 per 1000). Table III shows that mortality ratios decrease with years post injury as well as age.

\section{Causes of death}

Among the 362 subjects who had died during the study period, the organ system most frequently implicated in death was the genitourinary (GU) system. Eighty-eight individuals $-24.3 \%$ of all who died-died of GU related causes ( 71 cases of renal failure, 


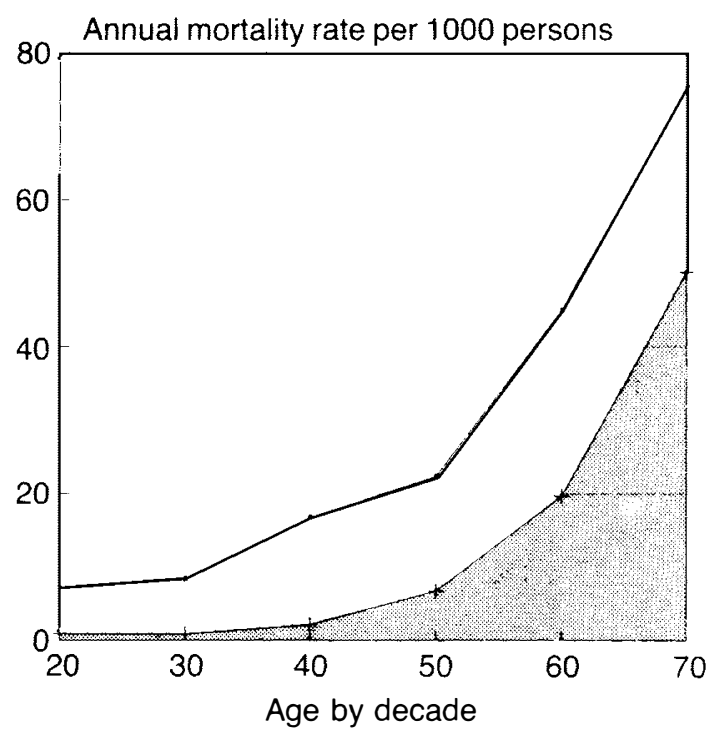

Figure 1 Annual mortality after SCI compared with general population. Top line $=$ aging study mortality rates (from the British study of aging with spinal cord injury). Bottom line $=1970$ OPCS gender matched mortality rates for England and Wales (from Office of Population Censuses and Surveys). The dark shaded area under the general population mortality curve (bottom line) represents the normal mortality increase due to aging among non disabled persons. The light shaded area between the two lines can be thought of as the extra increase in mortality due to spinal cord injury.

11 cases of pyelonephritis, and 6 other GU causes). Very closely following GU deaths were $84(23.2 \%)$ cardiovascular deaths (38 myocardial infarctions, 31 other diseases of the heart, 10 cases of cerebrovascular disease, and 5 cases of other circulatory problems). The respiratory system accounted for 50 deaths $(13.8 \%)$, with pneumonia being the most frequent. However, it is important to note that pneumonia is sometimes indicated on the death certificate when other, more specific causes are not known. Other major causes of death included $40(11.0 \%)$ neoplasms, $16(4.4 \%)$ cases of septicemia, $15(4.4 \%)$ digestive system disorders, 22 $(6.1 \%)$ accidents and injuries, and 38 $(10.5 \%)$ ill defined or non specific causes of death.

Table IV lists the leading causes of death
Table III Mortality ratios ${ }^{a}$ of persons with spinal cord injury compared with the general population by age and years post injury

\begin{tabular}{lccc}
\hline Years post injury & \multicolumn{3}{c}{ Age } \\
\hline & $15-34$ & $35-54$ & $55-84$ \\
$1-9$ & 9.2 & 6.4 & 3.5 \\
$10-19$ & 7.7 & 4.0 & 2.0 \\
$20-29$ & - b & 4.1 & 1.8 \\
$30+$ & $-{ }^{b}$ & 2.5 & 1.6 \\
\hline
\end{tabular}

a Mortality ratio equals the number of actual deaths in the spinal cord injured study group divided by the expected number of deaths for an age and gender matched sample of the general population computed using the 1970 mortality data for England and Wales from the Office of Population Censuses and Surveys. 1970 mortality data were utilized because that year represents the approximate mid point of the SCI data.

bIndicates no SCI study cases with the combination of age and years post injury.

for all of those who expired, as well as death causes for three categories of injury: (1) persons with paraplegia who do not have significant functional motor preservation below the injury, (2) persons with quadriplegia without functional motor preservation, and (3) persons with either paraplegia or quadriplegia who have significant functional motor preservation. The first group, persons with paraplegia, had the highest percentage of renal deaths and the lowest percentage of respiratory deaths. Persons with quadriplegia had the highest rate of respiratory and digestive system deaths as well as septicemia and deaths due to accidents and injuries. They had the lowest rate of cardiac deaths and neoplasms. The third group, those with very incomplete injuries regardless of neurological level, had the highest percentage of neoplasms and cardiac deaths and the lowest percentage of deaths due to accidents and injuries.

Two types of analyses were performed to better understand the impact of aging on causes of death. The first analyzed the percentage of various types of deaths occurring at different ages, different times post injury, and different eras of care. The second compared the spinal cord injury and 
Table IV Distribution of deaths by primary cause

\begin{tabular}{lrrrr} 
& & & \multicolumn{2}{c}{ Categories of injury } \\
Primary cause of death & All cases & Para ABC & Quad ABC & All D\&Es \\
\hline Genitourinary disorders & $88(24.3 \%)$ & $58(28.1 \%)$ & $12(21.1 \%)$ & $18(18.2 \%)$ \\
Cardiovascular diseases & $84(23.2 \%)$ & $48(23.2)$ & $8(14.1 \%)$ & $28(28.3 \%)$ \\
Septicemia & $16(4.4 \%)$ & $10(4.9 \%)$ & $4(7.0 \%)$ & $2(2.0 \%)$ \\
Neoplasms & $40(11.0 \%)$ & $21(10.2 \%)$ & $3(5.3 \%)$ & $16(16.2 \%)$ \\
Endocrine/blood disorders & $6(1.7 \%)$ & $3(1.5 \%)$ & $0(0.0 \%)$ & $3(3.0 \%)$ \\
Respiratory system disease & $50(13.8 \%)$ & $23(11.2 \%)$ & $11(19.3 \%)$ & $16(16.2 \%)$ \\
Digestive system disease & $16(4.4 \%)$ & $8(3.9 \%)$ & $4(7.0 \%)$ & $4(4.0 \%)$ \\
Nervous system disease & $2(0.6 \%)$ & $0(0.0 \%)$ & $1(1.8 \%)$ & $1(1.0 \%)$ \\
Accidents and injuries & $22(6.1 \%)$ & $13(6.3 \%)$ & $6(10.5 \%)$ & $3(3.0 \%)$ \\
Ill defined mortality & $38(10.5 \%)$ & $22(10.7 \%)$ & $8(14.0 \%)$ & $8(8.1 \%)$ \\
\hline
\end{tabular}

aPersons with paraplegia with Frankel ${ }^{22}$ grades $\mathrm{A}, \mathrm{B}$, or $\mathrm{C}$ (no functional motor preservation). ${ }^{b}$ Persons with quadriplegia with Frankel ${ }^{22}$ grades A, B, or C (no functional motor preservation). 'Persons with paraplegia or quadriplegia with Frankel ${ }^{22}$ grades D or E (functional motor preservation).

general population mortality rates for selected causes.

Genitourinary disorders comprised one of two causes of death that decreased in relative frequency over time. GU disorders accounted for $49 \%$ of the deaths occurring at age 30 to 39 , but only $11 \%$ of the deaths occurring over age 60; GU disorders accounted for $29 \%$ of the deaths occurring in the first 20 years post injury and only $9 \%$ of the deaths more than 30 years post injury; and GU disorders accounted for $43 \%$ of the deaths occurring in the 1940s and 1950s but only $10 \%$ of the deaths occurring in the 1980s and 1990s. This finding is consistent with that of others, ${ }^{23}$ who also found that renal deaths are no longer the primary cause of death in spinal cord injury. Deaths due to accidents and injuries also decreased in relative frequency over time, particularly with age. Of the deaths occurring prior to age $30,19 \%$ were in this category, while only $1 \%$ of deaths over age 50 were accidents or injuries.

On the other hand, cardiovascular and respiratory deaths became relatively more frequent with aging. Cardiovascular diseases were the most frequent causes of death among persons more than 30 years post injury ( $46 \%$ of all deaths) and among pcople over 60 years of age (35\% of deaths). These percentages for cardiovascular deaths are up sharply from the percentage of cardiovascular deaths at earlier ages and earlier periods post injury. Respiratory deaths increase dramatically with age but only slightly with years post injury.

Table $\mathrm{V}$ contrasts mortality rates for persons with spinal cord injury with the general population by age and selected causes of dẹath. Mortality due to neoplasms appears to be only slightly higher among persons with spinal cord injury than among the general population. Likewise, cardiovascular deaths roughly approximate the trend in the general population but with a somewhat greater rate at most ages. On the other hand, respiratory and genitourinary mortality rates are substantially higher for the spinal cord injured than the general population in almost all age groups.

\section{Morbidity}

Analysis of the over 19,000 diagnoses which occurred after the initial hospitalizations of the 834 study participants revealed that the most frequently occurring ICD-9 code was that for pressure sores. This diagnosis had an overall annual incidence of 23 per 100 , or $23 \%$. Decubiti showed an increased incidence with each 10 year increase in age after age 30 , but a decrease in incidence as the years post injury increased (Tables VI \& VII).

Urinary tract infections were the second 
Table $\mathbf{V}$ Annual mortality rate per 1000 persons with spinal cord injury compared with the general population $^{\text {a }}$ by age and cause of death

\begin{tabular}{|c|c|c|c|c|c|c|c|c|}
\hline Cause of death & Group & $15-24^{b}$ & $25-34$ & $35-44$ & $45-54$ & $55-64$ & $65-74$ & $75-84^{b}$ \\
\hline \multirow[t]{2}{*}{ All causes } & SCI & 7.2 & 8.4 & 16.7 & 22.4 & 45.0 & 75.1 & 229.6 \\
\hline & Pop & 0.9 & 0.9 & 2.2 & 6.7 & 19.7 & 50.2 & 113.3 \\
\hline \multirow[t]{2}{*}{ Neoplasms } & SCI & $-^{c}$ & $\ldots c$ & 1.2 & 3.1 & 6.6 & 11.4 & 25.5 \\
\hline & Pop & 0.1 & 0.2 & 0.5 & 1.9 & 5.9 & 12.4 & 19.1 \\
\hline \multirow[t]{2}{*}{ Cardiovascular diseases } & SCI & 0.8 & 0.7 & 2.4 & 4.4 & 13.3 & 21.2 & 102.0 \\
\hline & Pop & 0.1 & 0.2 & 0.8 & 3.2 & 9.4 & 25.1 & 61.4 \\
\hline \multirow[t]{2}{*}{ Respiratory diseases } & SCI & $-^{c}$ & 0.2 & 2.4 & 3.1 & 6.6 & 11.4 & 76.5 \\
\hline & Pop & 0.1 & 0.1 & 0.2 & 0.6 & 2.5 & 8.7 & 22.3 \\
\hline \multirow[t]{2}{*}{ Genitourinary diseases } & SCI & 1.6 & 2.7 & 5.7 & 5.4 & 9.0 & 11.4 & $-^{c}$ \\
\hline & Pop & 0.0 & 0.0 & 0.0 & 0.1 & 0.2 & 0.6 & 2.0 \\
\hline \multirow[t]{2}{*}{ Accidents and injuries } & SCI & 3.2 & 1.7 & 1.6 & 1.3 & 1.4 & 1.6 & $-^{c}$ \\
\hline & Pop & 0.5 & 0.4 & 0.4 & 0.5 & 0.6 & 0.8 & 2.1 \\
\hline
\end{tabular}

${ }^{a}$ Gender weighted 1970 mortality data for England and Wales from the Office of Population Censuses and Surveys. ${ }^{18}$ The approximate midpoint of the SCI data is 1970.

${ }^{b}$ Age groups of 15-24 and 75-84 only contain 9 SCI deaths each and are therefore less stable estimates than the other age groups containing 34 to 95 SCI deaths.

'Indicates that no SCI deaths occurred in the age group.

Table VI Incidence of follow up diagnoses and procedures by age (episodes per 100 cases per year)

\begin{tabular}{lrrrrr}
\hline & \multicolumn{5}{c}{ By age at episode } \\
& $<30$ & $30-39$ & $40-49$ & $50-59$ & $60+$ \\
\hline Diagnoses & & & & & \\
Infectious disease/neoplasm & 1.7 & 2.9 & 4.7 & 6.1 & 11.1 \\
CNS/seizure & 5.9 & 1.8 & 1.5 & 1.3 & 2.6 \\
Fainting/headache & 1.9 & 2.7 & 2.1 & 1.9 & 4.9 \\
Motor/sensory change & 2.0 & 1.5 & 1.9 & 2.1 & 2.3 \\
Disorder of eye/ear & .4 & 1.5 & 1.7 & 3.5 & 7.7 \\
Heart/circulatory & 2.0 & 2.9 & 5.2 & 8.1 & 19.3 \\
Pneumonia/atelectasis & 1.6 & 1.7 & 1.9 & 3.4 & 5.4 \\
Respiratory infection & 3.2 & 3.4 & 2.2 & 3.1 & 2.6 \\
Gastrointestinal & 5.3 & 7.7 & 9.0 & 8.9 & 15.3 \\
Hemorrhoids & 1.0 & 2.4 & 3.4 & 2.7 & 2.1 \\
Rectal abscess/bleeding & 1.3 & 2.5 & 3.5 & 2.9 & 2.1 \\
UTI & 19.7 & 20.1 & 19.0 & 17.1 & 27.8 \\
GU retention/hydronephrosis & 12.6 & 10.9 & 10.2 & 10.4 & 10.3 \\
Renal stone/failure & 3.4 & 4.8 & 3.8 & 6.0 & 8.3 \\
Male GU problem & 2.1 & 2.6 & 4.8 & 3.8 & 4.7 \\
Pressure sore & 25.5 & 20.4 & 22.0 & 24.5 & 27.4 \\
Muscle/joint pain & 5.2 & 6.9 & 11.8 & 9.0 & 10.2 \\
Spasticity/contracture & 5.5 & 5.3 & 5.5 & 4.4 & 4.7 \\
Fracture/sprain/amputation & 1.7 & 2.7 & 2.4 & 2.5 & 3.0 \\
Superficial wound & 2.8 & 1.9 & 1.7 & 1.5 & 2.1 \\
Injury/suicide & 1.5 & .8 & .8 & 1.3 & .6 \\
Operations & & & & & \\
Cardiac/Internal/CNS & 4.9 & 6.6 & 5.1 & 6.4 & 5.7 \\
Gastrointestinal & 1.9 & 4.9 & 4.5 & 3.9 & 5.3 \\
Genitourinary & 10.0 & 8.7 & 9.7 & 12.1 & 12.1 \\
Musculoskeletal & 3.0 & 2.9 & 4.7 & 3.3 & 4.7 \\
\hline - & & & & &
\end{tabular}


Table VII Incidence of follow up procedures and diagnoses by years post injury (episodes per 100 cases per year)

\begin{tabular}{|c|c|c|c|c|}
\hline & \multicolumn{4}{|c|}{ By years post injury } \\
\hline & $<10$ & $10-19$ & $20-29$ & $30+$ \\
\hline \multicolumn{5}{|l|}{ Diagnoses } \\
\hline Infectious disease/neoplasm & 2.4 & 4.4 & 7.3 & 10.7 \\
\hline CNS/seizure & 3.3 & 1.8 & 2.3 & 1.5 \\
\hline Fainting/headache & 2.0 & 3.0 & 2.6 & 1.8 \\
\hline Motor/sensory change & 1.7 & 1.5 & 2.6 & 2.8 \\
\hline Disorder of eye/ear & .8 & 1.1 & 5.4 & 10.3 \\
\hline Heart/circulatory & 2.9 & 5.4 & 10.0 & 14.2 \\
\hline Pneumonia/atelectasis & 2.4 & 2.3 & 2.4 & 2.0 \\
\hline Respiratory infection & 3.2 & 2.8 & 2.8 & 1.8 \\
\hline Gastrointestinal & 7.1 & 8.7 & 9.9 & 14.4 \\
\hline Hemorrhoids & 1.7 & 2.8 & 3.4 & 1.3 \\
\hline Rectal abscess/bleeding & 1.5 & 2.9 & 4.4 & 3.3 \\
\hline UTI & 17.3 & 22.8 & 22.0 & 13.8 \\
\hline GU retention/hydronephrosis & 12.7 & 9.3 & 10.3 & 8.1 \\
\hline Renal stone/failure & 3.7 & 5.5 & 5.4 & 6.3 \\
\hline Male GU problem & 2.8 & 3.1 & 4.6 & 7.2 \\
\hline Pressure sore & 27.7 & 20.1 & 19.4 & 16.6 \\
\hline Muscle/joint Pain & 5.8 & 7.0 & 11.3 & 16.0 \\
\hline Spasticity/contracture & 5.8 & 4.6 & 5.2 & 3.7 \\
\hline Fracture/sprain/amputation & 1.9 & 2.6 & 3.2 & 3.3 \\
\hline Superficial wound & 2.5 & 1.8 & 1.4 & .9 \\
\hline Injury/suicide & 1.2 & 1.1 & .8 & .4 \\
\hline \multicolumn{5}{|l|}{ Operations } \\
\hline Cardiac/internal/CNS & 6.8 & 4.5 & 6.6 & 4.6 \\
\hline Gastrointestinal & 2.1 & 5.7 & 5.7 & 5.3 \\
\hline Genitourinary & 8.9 & 9.5 & 12.2 & 17.3 \\
\hline Musculoskeletal & 2.6 & 3.9 & 5.1 & 5.8 \\
\hline
\end{tabular}

most frequently reported ICD-9 code with an overall annual incidence of $20 \%$. Urinary tract infections showed a dramatic increase in incidence among those age 60 and over (Table VI) and a slight increase in frequency between the 10th and 30th year post injury (Table VII). Although decubiti and urinary tract infections were by far the most frequently reported diagnoses, three patterns appeared among the less frequently encountered procedures and diagnoses. First, there were conditions which did not appear to be associated with aging. These diagnoses and procedures were most frequently encountered at early ages and in the first several years post injury. These included seizures and central nervous system disorders; urinary retention and hydronephrosis; spasticity and contractures; superficial wounds; and injuries and suicides.
Second, there was a set of conditions more strongly associated with aging than with years post injury. This included operations of the cardiac, internal, and nervous systems; pneumonia, atelectasis, respiratory infections, and dyspnea; renal stones and failure; and fainting and headaches (Table VI).

Third, a variety of conditions were more strongly associated with increasing years post injury than with increasing age. This list was comprised of musculoskeletal problems-identified as tendon and joint procedures, and muscle and joint pain and stiffness - as well as rectal abscesses and bleeding and, among men, GU problems (Table VII).

Finally there is a substantial number of conditions that appeared most frequently in both the oldest age group ( 60 and over) and 
the group that was longest post injury (30 years and over). These included a wide range of gastrointestinal problems and operations, hemorrhoids, nausea, and vomiting. Other frequently encountered conditions included genitourinary operations, infectious and neoplastic diseases, motor or sensory loss, disorders of the eye or ear, cardiovascular conditions, and fractures and dislocations (Table VI \& VII).

\section{Current health status}

Assessment of the 282 survivors who returned to the SCI center for a day of comprehensive reevaluation revealed that those subjects with spinal cord injuries at T6 and above had significantly lower systolic and diastolic blood pressures than non disabled persons. On the other hand, persons with spinal cord injury below T-6 had slightly elevated systolic pressures and significantly elevated diastolic pressures. Also, statistically significant differences in creatinine were found with serum creatinine levels being significantly lower among all groups of persons with spinal cord injuries compared to their non disabled counterparts. Among other laboratory results, small differences were noted periodically among various subgroups of spinal cord injured persons. However, with the exception of creatinine, even when these differences were statistically significant they were relatively small, were still within normal ranges, and did not appear to form a clear pattern of major differences associated with aging in spinal cord injury.

During the physical examination, 63 persons with pressure sores ( $22 \%$ of the group) were identified. They had a total of 99 decubiti, 15 of which were classified as grade 3 or 4 on the Shea Scale. ${ }^{24}$ The incidence of scoliosis was $14 \%$, as was the incidence of kyphosis. It was also noted that $30 \%$ of the subjects had restricted neck flexion, more than $10 \%$ had losses in shoulder range of motion, $55 \%$ had insufficient hip abduction, and $27 \%$ had hip flexion contractures. Spasticity of grade 4 and above on the Ashworth Tone Scale ${ }^{25}$ was documented in $18 \%$ of the group.

To augment the physical examination, the detailed health status interview focused on the respondents' perception of the aging process. Although $77 \%$ reported feeling generally healthy, a significant percentage of the respondents reported a variety of health problems which they interpreted as interfering with their health and functional status. Over $40 \%$ of those interviewed reported that they needed changes in their adaptive equipment. Twenty-two percent required increased physical assistance. Others reported postural changes, constipation, or urinary tract infections that required treatment. Each of the following problems was reported by at least one quarter of the subjects: hematuria, diarrhea, stomach or intestinal pain, changes in sexual function, elevated blood pressure, skin dryness, changes in temperature control, pain that limited independence, and fractures.

\section{Psychosocial findings and quality of life} Within the group of 282 survivors participating in the health status interview, total CHART scores of individuals under 50 years old averaged 49 points higher than the scores of individuals 50 and over. These differences were statistically significant $(p<.05)$. For the individual CHART subscales measuring physical independence, mobility, and occupation, the differences between these age groups also were statistically significant $(p<.05)$. In terms of years post injury, however, no statistically significant differences were found in any of the CHART subscores or in the total CHART score. Finally, by level of injury, those with quadriplegia were significantly $(p<.05)$ more handicapped (ie, they had lower CHART scores) while people with neurologically incomplete injuries were the least handicapped.

Approximately three quarters of the subjects rated their current quality of life as either good or excellent on a 5-point scale. A similarly favorable response was reported for a period 10 years ago, but only $56 \%$ reported a favorable response 20 years ago. However, further analysis revealed that these seemingly improving quality of life ratings over time generally were limited to the younger study group members. The largest improvement in quality of life was 
reported by those subjects with the least aging effect (ie, those less than 50 years old and injured less than 30 years). On the other hand, those individuals with the greatest aging impact (over 50 years old and injured 30 or more years) reported the largest decline in quality of life. This suggests a pattern of increasing quality of life up to age 50 and 30 years post injury, followed by slight declines after that.

Analysis of scores for the Index of Psychological Wellbeing revealed no statistically significant differences in terms of neurological grouping (paraplegia, quadriplegia, incomplete), age, or years post injury.

On the other hand, there were significant differences in scores on the Life Satisfaction Index with respect to age. Those under age 50 reported significantly better life satisfaction than the older group. Those injured less than 30 years also reported better life satisfaction, but not significantly so. This index, like the 5-point quality of life rating and the Index of Psychological Wellbeing. revealed no significant differences by level of injury.

Finally, on the Quality of Life and Individual Needs Questionnaire, the 282 subjects rated the importance of expressing themselves, and the importance of reading, music, and entertainment substantially higher than the general non disabled population. Involvement in civic activities was rated as less important. The study subjects also attached greater importance to helping others, learning, socializing, and participating in active recreation than their non disabled counterparts, but considered material comforts, having children, and work somewhat less important.

Regarding how well they felt their needs were met in each of these areas, the spinal cord injury survivors reported that it was the need to have and raise children that was least well met. Other needs that were not well met included the need for relationships with friends, helping others, involvement in civic activities, and work. On the other hand, needs in the areas of reading, listening to music, and observing sporting events and entertainment were better met for these spinal cord injured subjects.

\section{Discussion}

There is a clear interplay between the normal aging process and the consequences of spinal cord injury. This results in less than normal life spans, increasing medical complications with the aging process, a wide array of increasing physical limitations, and psychosocial consequences occurring over the decades post injury. Nonetheless, the results of this comprehensive study of aging with a spinal cord injury indicate that many persons with spinal cord injury are now surviving several decades with relatively good outcomes.

In terms of life expectancy, the survival times found in this investigation, while still substantially less than life expectancies in the general population, are relatively comparable with those of Geisler et $a^{26,27}$ and other researchers ${ }^{28}$ who estimated survival after discounting early deaths which occurred during the initial hospitalization. Compared with those SCI survival calculations which did include initial hospitalization deaths, ${ }^{3}$ the survival rates reported here are considerably better. It is important to note, however, that unlike preceding studies, which used actuarial techniques to statistically project life expectancies based on mortality ratios established over relatively short time periods, ${ }^{26-28}$ the survival rates described in this report are based on actual survival outcomes over longer periods of time. In any case, the survival in this population is particularly impressive when considering that all cases in the investigation were injured more than 20 years ago when the quality of initial acute and rehabilitative care had not achieved current levels.

Generally, in this sample the extent of neurological impairment appears to be related to survival and causes of death. Renal deaths were greatest among those with paraplegia while respiratory deaths were most frequent among those with quadriplegia. However, the most dramatic evidence correlating long term survival with the neurological deficit was the observation that those with injuries that were initially incomplete experienced illness and survival patterns most like those of the general population. 
Additionally, and perhaps more important, it appears that as time passes the causes of death among those who survive long term with spinal cord injuries - regardless of the severity of their neurologic impairments-move away from traditional SCI related causes of death, such as renal failure, and begin to approximate the causes of death of the general population. Causes of morbidity also seem to show that except for a few disability related issues-particularly skin breakdown and urinary tract infections - the illnesses which are problematic for SCI survivors mirror those of the general population. It is important to keep in mind, however, that deaths among these SCI survivors - and the illnesses that lead to those deaths - are occurring at younger ages than one would expect within the non disabled population.

Some limitations do exist for both the mortality and mobidity data within this study. First, the primary causes of death were taken from death certificates; autopsies were rarely performed. The primary causes of death documented may not have included significant comorbidities and contributing causes. Second, morbidity data were gathered from all available sources. While many subjects did return to the SCI center for regular follow up and utilized the center as their exclusive source of care, many others received portions of their care elsewhere. For the latter, therefore, it is likely that the medical history was incomplete; for example, frequently occurring, but relatively minor conditions, such as urinary tract infections, may not have been fully documented. In addition to the unknown impact on the data of these and other undocumented morbidities, there may even be under-documentation of problems among those who were followed closely and seen for reassessment. Specifically, conditions which may be chronic in nature - such as spasticity, contractures, and pain-may not continue to be documented over time. Many individuals simply become accustomed to such problems and stop reporting them to their physicians.

Another limitation of the data reported here lies in the inherent confounding effects of aging and disability in individuals who are experiencing both simultaneously. Although some illnesses are more related to age than to chronicity of the injury, and others seem more dependent upon the duration of disability, it is impossible to entirely separate the effects of age from effects of chronic disability.

It is primarily in the psychosocial arena, particularly in the measurement of handicap, that the roles of age versus duration of disability become somewhat more clear cut. CHART data indicate that handicap-or the lack of social integration-increases with age but not with years post injury. This is also true of the general population: as individuals age they require more assistance, move about in their communities less, and are less active socially and vocationally. What is concerning about this finding, however, is that it appears that this withdrawal or disengagement may be occurring considerably earlier in persons with spinal cord injuries.

Analysis of the results of the administration of the subjective 5-point quality of life scale and the Life Satisfaction Index may be a reflection of the above: increasing handicap and isolation may lead to decreased satisfaction with life itself, as reported by the oldest and longest injured subjects.

It is perhaps this area of life satisfaction over time that demands additional study. The results of the Quality of Life and Individual Needs Questionnaire, in particular, raise intriguing questions. Although there were differences between subgroups of SCI survivors compared by age, chronicity, or level and severity of injury, the differences found when all of the SCI survivors are compared with the general population were far more significant. Not only did they rank their needs differently, but they also differed in how well they felt those needs were met. In particular, those needs that were least well met also seemed to be ranked relatively lower in importance. Thus, although it was initially concerning that SCI survivors' needs are not being met in such areas as family, child rearing, and relationships, it is noteworthy that these survivors also attached less importance to these things. This raises the possibility that as a group, survivors of SCI may experience 
a shifting in priorities because of their long term physical disabilities.

In any case, it is clear that people with spinal cord injuries in this investigation, despite the described health issues, are relatively happy with the quality of their lives. The extent to which this contentment is related to health, increased survival rates and durations, or changing life priorities is an area that requires further discussion and investigation.

\section{Acknowledgments}

This research was made possible by grant H133.G90010 from the United States National
Institute for Disability and Rehabilitation Research, Washington DC.

Vivien Salisbury and Dr John Silver of Stoke Mandeville Hospital, and Professor N Wald of St Bartholemew's Hospital, London, are to be acknowledged and thanked for the important preliminary work they did with the Office of Population Censuses and Surveys. Their efforts greatly facilitated the identification and confirmation of deaths within the study sample.

The authors also wish to thank the staff at the National Spinal Injuries Centre (NSIC) and Regional Spinal Injuries Centre (RSIC) for their assistance with this investigation. Particular thanks are extended to Jean Mason, Wendy Reay and Ebba Bergstrom at the NSIC; and to Samantha Turner, Sandra Cribb and Jacqui Heaton at the RSIC.

\section{References}

1 Menter RR (1990) Aging and spinal cord injury: implications for existing model systems and future federal, state and local health care policy. In: Apple DF, Hudson LM, editors. Spinal Cord Injury: The Model. Proceedings of the National Consensus Conference on Catastrophic Illness and Injury. The Georgia Regional Spinal Cord Injury Care System, Shepherd Center for Treatment of Spinal Injuries Inc, Atlanta, Georgia.

2 Kurtzke JF (1975) Epidemiology of spinal cord injury. Exp Neuro 3(2): 163-236.

3 Kennedy EJ, editor (1986) Spinal Cord Injury: Facts and Figures. University of Alabama, Birmingham, Alabama.

4 Young JS, Burns PE, Brown AM, McCutchen R (1982) Spinal Cord Injury Statistics: Experience of the Model Systems. Good Samaritan Medical Center, Phoenix, Arizona.

5 DeVivo MJ (1990) Life expectancy and causes of death for persons with spinal cord injuries. In Apple DF, Hudson LM, editors. Spinal Cord Injury: The Model. Proceedings of the National Consensus Conference on Catastrophic Injury. The Georgia Regional Spinal Cord Injury Care System. Shepherd Center for Treatment of Spinal Injuries Inc, Atlanta, Georgia.

6 Whiteneck GG (1990) The high costs of high-level quadriplegia. In Apple DF, Hudson LM, editors. Spinal Cord Injury: The Model. Proceedings of the National Consensus Conference on Catastrophic Illness and Injury. The Georgia Regional Spinal Injury Care System, Shepherd Center for Treatment of Spinal Injuries Inc, Atlanta, Georgia.

7 Berkowitz M (in press) The Economic Consequences of Traumatic Spinal Cord Injury. Demos Publications, New York.

8 Creek G, Moore M, Oliver M, Salisbury J, Zarb G (1987) Personal and Social Implications of Spinal Cord Injury: A Retrospective Study. Thames Polytechnic, London.

9 Hoad A, Oliver MJ, Silver JR (1990) The Impact of Spinal Injury on Primary Carers. Thames Polytechnic, London.

10 Zarb GJ, Oliver MJ, Silver JR (1990) Ageing with Spinal Cord Injury: The Right to a Supportive Environment? Thames Polytechnic/Spinal Injuries Association, London.

11 Corbet B (1980) Options: Spinal Cord Injury and the Future. A B Hirschfeld Press, Denver, Colorado.

12 Hohmann G (1982) Fifth Annual John Young S. Lectureship. Craig Hospital, Englewood, Colorado.

13 Trieschmann RB (1987) Aging with a Disability. Demos Publications, New York.

14 Cutler SJ, Ederer F (1958) Maximum utilization of the life table method in analyzing survival. J Chron Dis 8: $699-712$.

15 Cox DR (1972) Regression models and life tables. J R Stat Soc 34(B): 187-220.

16 The International Classification of Diseases. 9th Ed. Clinical Modification (1978) Commission on Professional and Hospital Activities. Ann Arbor, Michigan.

17 Office of Population Censuses and Surveys (1971) Death rates per million from principal causes by sex and age group, for England and Wales, 1970. Mortality Statistics Series DH2 OPCS, London.

18 Whiteneck GG, Charlifue SW, Gerhart KA, Overholser JA, Richardson GN (in press) Quantifying handicap: a new measure of long-term rehabilitation outcomes. Arch Phys Med Rehabil.

19 Berkman PL (1971) Measurement of mental health in a general population survey. Am J Epidemiol 94(2): $105-111$. 
20 Wood V, Wylie ML, Sheafor B (1969) An analysis of a short self-report measure of life satisfaction: correlation with rater judgments. J Gerontol 24(4): 465-469.

21 Flanagan JC (1978) A research approach to improving our quality of life. Am Psychologist 2: 138-147.

22 Frankel H, Hancock D, Hyslop G, Melzak LS, Michaelis GH, Ungar JDS et al (1969) The value of postural reduction in the initial management of closed injuries to the spine with paraplegia and tetraplegia. Paraplegia 7: 179-192.

23 DeVivo MJ, Kartus PL, Stover SL, Rutt RD, Fine PR (1989) Cause of death for patients with spinal cord injuries. Arch Intern Med 149: 1761-1766.

24 Shea JD (1975) Pressure sores: classification and management. Clin Orthop 112: 89-100.

25 Hattas JR (1980) Review of European clinical trials with baclofen. In: Feldman RG, Young RR, Koella WP, editors. Spasticity: Disordered Motor Control. Miami Symposia Specialist: 71-75.

26 Geisler WO, Jousse AT, Wynne-Jones M (1977) Survival in traumatic transverse myelitis. Paraplegia 14: 262-275.

27 Geisler WO, Jousse AT, Wynne-Jones M, Breithaupt D (1983) Survival in traumatic spinal cord injury. Paraplegia 21: 364-373.

28 DeVivo MJ, Fine PR, Maetz HM, Stover SL (1980) Prevalence of spinal cord injury: a reestimation employing life table techniques. Arch Neurol 37: 707-708. 